\title{
ENSAIOS DA ESCOLA DO TRABALHO NAS ESCOLAS ITINERANTES DOS ACAMPAMENTOS DO MST NO ESTADO DO PARANÁ
}

\author{
EXPERIMENTS OF THE SCHOOL OF WORK IN THE ITINERANT \\ SCHOOLS OF THE MST CAMPS IN THE STATE OF PARANÁ
}

\begin{abstract}
Alessandro Santos Mariano ${ }^{1}$ José Claudinei Lombardi²

\section{RESUMO}

O objetivo deste artigo é apresentar elementos da Proposta Curricular das Escolas Itinerantes do Paraná, escolas públicas de educação básica, gestadas e orientadas pelo projeto educativo do Movimento dos Trabalhadores Sem Terra (MST), que tem o trabalho como matriz formativa, se fundamentando em Marx (1987), na pedagogia socialista e na pedagogia do oprimido (FREIRE, 1982). Essa proposta resgata práticas de educação e de escola, desenvolvidas pela classe trabalhadora, desde a Revolução Russa, com a experiência da Escola do Trabalho, sistematizada pelos autores Pistrak (2000 \& 2009) e Shulgin (2013). A teoria produzida no processo de luta da classe trabalhadora foi incorporada de maneira crítica nas Escolas Itinerantes do Paraná, avançando em proposições e, principalmente, apontando caminhos para uma nova forma escolar desde as práticas de autoorganização e trabalho socialmente necessário. Representam um processo contra-hegemônico uma vez que buscam, num contexto de luta pela Reforma Agrária, exercitar uma proposta de currículo, que tem por perspectiva contribuir para um processo de formação humana em todas as dimensões e constitui um processo de auto-gestão da classe trabalhadora.
\end{abstract}

Palavras-chaves: Trabalho; Complexos de Estudo; Escola Itinerante; MST

\section{ABSTRACT}

The objective of this article is to present elements of the Curriculum Proposal of the Parana Itinerant Schools, public schools, basic education, and educated and guided by the educational project of the Landless Workers Movement (MST), which has the work as a formative Matrix, Marx (1987), socialist pedagogy and the pedagogy of the oppressed (FREIRE, 1982). This proposal rescues practices of education and school, developed by the working class, since the Russian Revolution, with the experience of the School of Work systematized by the authors Pistrak (2000 \& 2009) and Shulgin (2013). The theory produced in the process of struggle of the working class was incorporated in a

\footnotetext{
${ }^{1}$ Doutorando em Educação pela Faculdade de Educação UNICAMP. Membro do Coletivo Nacional de Educação do MST. e-mail: alessandromstpr@gmail.com

${ }^{2}$ Doutor em Educação pela Universidade Estadual de Campinas.Professor Titular do DEFHE, Faculdade de Educação UNICAMP. e-mail: jcl.zezo@gmail.com
} 
critical way, in the Itinerant Schools of Paraná, advancing in propositions and, mainly pointing out ways to a new school form from the practices of self-organization and socially necessary work. They represent a counter-hegemonic process, since it seeks, in a context of struggle for Agrarian Reform, to exercise an proposal of curriculum, whose perspective is to contribute to a process of human formation in all dimensions and represents a process of self-management of the working class.

Keywords: Work; Study Complexes; Itinerant School; MST

\section{INTRODUÇÃO}

Esse artigo tem por objetivo apresentar a concepção e fundamentos da Proposta Curricular, que vem sendo desenvolvida desde 2003, nas Escolas Itinerantes do Paraná, que são escolas públicas, pensadas e gestadas pelo Movimento dos Trabalhadores Rurais Sem Terra (MST), com a interface da política estatal de educação.

O MST, em seus 34 anos de existência (1984-2018), além de fazer a luta por terra e Reforma Agrária, concebeu um projeto de educação que tem o trabalho como matriz formativa, com a perspectiva de contribuir para um processo de formação humana em todas as dimensões, tornando-se instrumento para um possível processo de emancipação humana.

A Escola Itinerante emergiu da luta pelo direito à educação dentro dos acampamentos e assentamentos do MST, deriva da negação do direito à escola para as crianças Sem Terra, mas também da necessidade de uma escola que pudesse acompanhar as famílias Sem Terra nos diversos espaços de luta, como as ocupações e marchas, ou seja, uma escola comprometida com a luta por Reforma Agrária, com a construção de outra forma societária, com igualdade e justiça social.

A Escola Itinerante tem origem nas primeiras experiências de escolas dos acampamentos, que existiram e existem nesses espaços de luta pela terra em todo o Brasil. Duas experiências importantes estão na origem dessa escola no MST, os acampamentos da Encruzilhada Natalino, em 1978 e a Fazenda Anonni, em 1979, ambos localizados no Rio Grande do Sul, os quais foram fundamentais para constituição do próprio MST. Esses dois acampamentos decidiram organizar uma Escola, em função da preocupação com as mais de 600 crianças fora da escola nesses espaços, pois o poder público não garantia o direito à 


\section{Revista \\ Debates Insubmissos}

escola a quem estava em situação de acampamento e quando isso ocorria, em geral, era de forma a levar as crianças dos acampamentos para as escolas na sede dos municípios. (CAMINI, 2009)

No Estado do Paraná, a Escola Itinerante teve o reconhecimento legal em 2003, resultado de mobilizações e pressões ao poder público ${ }^{3}$. De acordo com Mariano (2015), nesse período haviam 14.000 famílias acampadas no estado, e muitas crianças estavam sem escola. Na jornada de lutas, em abril de 2003, reunindo em média cinco mil integrantes do MST acampados em Curitiba, além de ter na pauta de reivindicação o assentamento de todas as famílias, exigia-se a escola para os acampamentos.

Fruto dessa pressão, a Secretaria de Estado da Educação do Paraná encaminhou a proposta de criação das Escolas Itinerantes ao Conselho Estadual de Educação, que aprovou a formação das mesmas em dezembro de 2003. Dessa forma, em 2004 foram criadas quatro escolas, que passaram a atender cerca de 1200 estudantes, em sua maioria Educação Infantil e anos inicias da Educação Fundamental.

De 2003 a 2018, num percurso de 15 anos de funcionamento, já foram criadas 22 escolas, estimando o atendimento a pelo menos 20 mil estudantes na Educação Infantil, Ensino Fundamental e Médio, de acordo com dados do Setor de Educação do MST/PR. No quadro a seguir apresentamos todas as Escolas Itinerantes criadas em acampamentos, no Paraná, de 2003 em diante e a situação em que se encontrava em 2018:

\footnotetext{
${ }^{3}$ Segundo Mariano (2008, p.33), na medida em que o MST pressiona os governos pela legalização da Escola Itinerante, obriga o Estado a reconhecer, bem como a deliberar uma política social, passando a fazer parte de suas ações governamentais, ou seja, ela é fruto da pressão que os trabalhadores(as) fazem ao governo, ao Estado.
} 
Quadro 1 - Escolas Itinerantes do Paraná, criadas a partir de 2003 e situação em 2018

\begin{tabular}{|c|c|c|c|c|}
\hline $\begin{array}{l}\text { ESCOLA } \\
\text { ITINERANTE/ } \\
\text { NÍVEL DE } \\
\text { EDUCAÇÃO } \\
\text { OFERTADO }\end{array}$ & $\begin{array}{c}\text { ANO DE } \\
\text { CRIAÇÃO } \\
\text { DA } \\
\text { ESCOLA }\end{array}$ & MUNICÍPIO & ACAMPAMENTO & $\begin{array}{l}\text { SITUAÇÃO EM } 2018 \text { OU } \\
\text { PERÍODO ANTERIOR }\end{array}$ \\
\hline $\begin{array}{l}\text { Chico Mendes } \\
\text { Educação Infantil, } \\
\text { Ensino Fundamental } \\
\text { e Ensino Médio }\end{array}$ & 2003 & & $\begin{array}{l}\text { José Abílio dos } \\
\text { Santos }\end{array}$ & $\begin{array}{l}\text { Em } 2007 \text { tornou-se Colégio Estadual } \\
\text { do Campo Chico Mendes, no } \\
\text { assentamento Celso Furtado. }\end{array}$ \\
\hline $\begin{array}{c}\text { Olga Benário } \\
\text { Prestes } \\
\text { Educação Infantil, } \\
\text { Ensino Fundamental } \\
\text { e Médio }\end{array}$ & 2003 & $\begin{array}{l}\text { Quedas do } \\
\text { Iguaçu }\end{array}$ & Dez de Maio & $\begin{array}{l}\text { Em } 2007 \text { tornou-se Colégio Estadual } \\
\text { Olga Benário Prestes, no } \\
\text { assentamento Celso Furtado. }\end{array}$ \\
\hline $\begin{array}{l}\text { Zumbi dos Palmares } \\
\text { Educação Infantil, } \\
\text { Ensino Fundamental } \\
\text { e Médio }\end{array}$ & 2003 & Cascavel & Primeiro de Agosto & $\begin{array}{l}\text { Escola de Assentamento (em } \\
\text { funcionamento como: Escola } \\
\text { Municipal Zumbi dos Palmares e } \\
\text { Colégio Estadual Aprendendo com a } \\
\text { Terra e com a Vida). }\end{array}$ \\
\hline $\begin{array}{c}\text { Antônio Tavares } \\
\text { Educação Infantil e } \\
\text { Anos Iniciais }\end{array}$ & 2003 & $\begin{array}{l}\text { Espigão Alto } \\
\text { do Iguaçu }\end{array}$ & Segunda Conquista & $\begin{array}{l}\text { A escola encerrou as atividades em } \\
2006 \text {, devido ao despejo e ao } \\
\text { número reduzido de educandos(as) } \\
\text { que então passaram a frequentar as } \\
\text { escolas da cidade. }\end{array}$ \\
\hline $\begin{array}{c}\text { Paulo Freire } \\
\text { Educação Infantil e } \\
\text { Anos Iniciais }\end{array}$ & 2003 & Paula Freitas & $\begin{array}{l}\text { Primeiro de Maio e } \\
\text { depois Reduto de } \\
\text { Caraguatá }\end{array}$ & $\begin{array}{l}\text { Em 2007, itinera com as famílias } \\
\text { para o Acampamento Reduto de } \\
\text { Caraguatá. Continua escola de } \\
\text { acampamento. }\end{array}$ \\
\hline $\begin{array}{l}\text { Carlos Marighella } \\
\text { Educação Infantil e } \\
\text { Ensino Fundamental }\end{array}$ & 2004 & $\begin{array}{l}\text { Planaltina do } \\
\text { Paraná }\end{array}$ & $\begin{array}{c}\text { Elias Gonçalves } \\
\text { Meura }\end{array}$ & $\begin{array}{l}\text { Itinerou para o município de } \\
\text { Carlópolis, após a reintegração de } \\
\text { posse da Fazenda Santa } \\
\text { Filomena em abril de } 2013 \text {. }\end{array}$ \\
\hline $\begin{array}{c}\text { Ernesto Che } \\
\text { Guevara } \\
\text { Educação Infantil e } \\
\text { Anos Iniciais }\end{array}$ & 2004 & Guairaçá & Oito de Março & $\begin{array}{l}\text { Esta escola itinerou por vários } \\
\text { acampamentos e municípios - } \\
\text { Quilombo dos Palmares/Jardim } \\
\text { Olinda março de } 2007 \text { (Fazenda } \\
\text { Videira), em março de } 2008 \text { foi para } \\
\text { o Acampamento Oito de } \\
\text { Março/Guairacá. Todas as saídas das } \\
\text { ocupações foram geradas por } \\
\text { despejos. Encerrou suas atividades } \\
\text { em 2009, com um despejo. }\end{array}$ \\
\hline
\end{tabular}




\begin{tabular}{|c|c|c|c|c|}
\hline $\begin{array}{c}\text { Sementes do } \\
\text { Amanhã } \\
\text { Educação Infantil e } \\
\text { Anos Iniciais }\end{array}$ & 2004 & Matelândia & Chico Mendes & $\begin{array}{l}\text { Escola encerrada em 2014, em } \\
\text { função de limites organizativos do } \\
\text { acampamento. }\end{array}$ \\
\hline $\begin{array}{l}\text { Anton Makarenko } \\
\text { Educação Infantil e } \\
\text { Anos Iniciais }\end{array}$ & 2005 & Amaporã & $\begin{array}{l}\text { Pré-Assentamento } \\
\text { Companheira } \\
\text { Roseli Nunes }\end{array}$ & $\begin{array}{l}\text { Em } 2008 \text { a escola encerrou suas } \\
\text { atividades devido à criação do } \\
\text { assentamento. }\end{array}$ \\
\hline $\begin{array}{l}\text { Caminhos do Saber } \\
\text { Educação Infantil, } \\
\text { Ensino Fundamental } \\
\text { e Médio }\end{array}$ & 2007 & Ortigueira & Maila Sabrina & Continua escola de acampamento. \\
\hline $\begin{array}{c}\text { Oziel Alves } \\
\text { Educação Infantil e } \\
\text { Anos Iniciais }\end{array}$ & 2007 & Cascavel & Casa Nova & 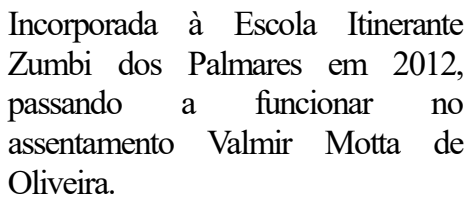 \\
\hline $\begin{array}{c}\text { Terra Livre } \\
\text { Educação Infantil e } \\
\text { Anos Iniciais }\end{array}$ & 2007 & Cascavel & Terra Livre & $\begin{array}{l}\text { Despejada e encerrou as atividades } \\
\text { em } 2008 .\end{array}$ \\
\hline $\begin{array}{l}\text { Novos Caminhos do } \\
\text { Campo } \\
\text { Educação Infantil e } \\
\text { Anos Iniciais }\end{array}$ & 2007 & Céu Azul & Quatro de Setembro & $\begin{array}{l}\text { Encerrou as atividades em 2008, } \\
\text { devido à itinerância de algumas } \\
\text { famílias que foram assentadas em } \\
\text { Cascavel, os educandos(as) } \\
\text { frequentam as escolas da cidade. As } \\
\text { demais famílias itineraram para os } \\
\text { acampamentos de Jacarezinho, } \\
\text { Londrina e Porecatu, os } \\
\text { educandos(as) frequentam as } \\
\text { Escolas Itinerantes desses locais. }\end{array}$ \\
\hline $\begin{array}{l}\text { Valmir Mota de } \\
\text { Oliveira } \\
\text { Educação Infantil, } \\
\text { Ensino Fundamental } \\
\text { e Médio }\end{array}$ & 2009 & Jacarezinho & $\begin{array}{l}\text { Valmir Mota de } \\
\text { Oliveira }\end{array}$ & $\begin{array}{l}\text { Continua escola de acampamento, } \\
\text { mas funcionando no pré- } \\
\text { Assentamento Valmir Mota de } \\
\text { Oliveira. }\end{array}$ \\
\hline $\begin{array}{l}\text { Construtores do } \\
\text { Futuro } \\
\text { Educação Infantil, } \\
\text { Ensino Fundamental }\end{array}$ & 2010 & $\begin{array}{l}\text { Rio Branco do } \\
\text { Ivaí }\end{array}$ & $\begin{array}{l}\text { Primeiro de } \\
\text { Setembro }\end{array}$ & Continua escola de acampamento. \\
\hline $\begin{array}{l}\text { Herdeiros da Luta de } \\
\text { Porecatu } \\
\text { Educação Infantil } \\
\text { Anos Iniciais }\end{array}$ & 2010 & Porecatu & Herdeiros da Luta & Continua escola de acampamento. \\
\hline
\end{tabular}




\begin{tabular}{|c|c|c|c|c|}
\hline $\begin{array}{l}\text { Maria Aparecida } \\
\text { RosignolFranciosi } \\
\text { Educação Infantil, } \\
\text { Educação } \\
\text { Fundamental e } \\
\text { Ensino Médio }\end{array}$ & 2010 & Londrina & Guairacá & $\begin{array}{l}\text { Escola de Assentamento (Escola } \\
\text { Municipal Maria Aparecida } \\
\text { RosgnolFranciosi e } \\
\text { Estadual Eli Vive). }\end{array}$ \\
\hline $\begin{array}{l}\text { Herdeiros da Terra } \\
\text { Educação Infantil e } \\
\text { Educação } \\
\text { Fundamental e } \\
\text { Ensino Médio }\end{array}$ & 2014 & $\begin{array}{l}\text { Rio Bonito do } \\
\text { Iguaçu }\end{array}$ & $\begin{array}{l}\text { Herdeiros da Terra, } \\
\text { Primeiro de Maio }\end{array}$ & $\begin{array}{l}\text { Funciona no Acampamento } \\
\text { Herdeiros da Luta do Primeiro de } \\
\text { Maio e como extensão estão em } \\
\text { mais três acampamentos, que foram } \\
\text { subdivisões deste acampamento. }\end{array}$ \\
\hline $\begin{array}{l}\text { Semeando o Saber } \\
\text { Educação Infantil e } \\
\text { Anos Iniciais }\end{array}$ & 2014 & Florestópolis & Zilda Arns & $\begin{array}{l}\text { Funcionando como escola de } \\
\text { acampamento }\end{array}$ \\
\hline $\begin{array}{l}\text { Vagner Lopes } \\
\text { Educação Infantil, } \\
\text { Educação } \\
\text { Fundamental e } \\
\text { Ensino Médio }\end{array}$ & 2015 & $\begin{array}{l}\text { Quedas do } \\
\text { Iguaçu }\end{array}$ & $\begin{array}{l}\text { Dom Tomas } \\
\text { Bauduino }\end{array}$ & $\begin{array}{l}\text { Funciona no Acampamento Dom } \\
\text { Tomás Bauduìno, tendo uma } \\
\text { extensão de escola num } \\
\text { acampamento derivado do mesmo. }\end{array}$ \\
\hline
\end{tabular}

Fonte: Mariano (2016)

Estas Escolas Itinerantes ofertam a educação básica em acampamentos de famílias Sem Terra do Estado do Paraná com uma proposta curricular organizada em Complexos de Estudo. O contexto de luta no qual se encontram as empurram a exercitar uma proposta de currículo que articula trabalho, ensino e auto-organização dos estudantes. Por ser vinculada à rede estadual de ensino, seus professores(as) são contratados mediante contrato temporário, para a Educação Infantil (4 e 5 anos) e anos Iniciais da Educação Fundamental (6 a 10 anos), são professores unidocentes formados no curso normal de nível médio (magistério) ou pedagogia. E para os anos finais da Educação Fundamental (11 a 14 anos) e Ensino Médio (15 a 17 anos), os professores(as) são licenciados nas diversas disciplinas existentes na grade curricular.

Esse artigo é resultado de uma dissertação de mestrado, que contou com uma incursão investigativa composta por revisão bibliográfica e análise documental, realizada nos anos de 2015 e 2016 nas Escolas Itinerantes do Paraná, com o objetivo de compreender os fundamentos e a estrutura da Proposta Curricular dessas escolas. 
Os resultados dessa pesquisa, que aqui compartilhamos, estão organizados em quatro partes. Na primeira, apresentamos o processo de construção da proposta curricular; na segunda, refletimos sobre a matriz do trabalho; na terceira, discorremos sobre os fundamentos teórico-metodológicos da Proposta Curricular e finalizamos com a auto-organização dos estudantes e a nova forma escolar proposta.

\section{A CONSTRUÇÃo da PROPOSTA CURRICULAR EM COMPLEXOS DE ESTUDOS}

As Escolas Itinerantes do Paraná, desde 2003, foram criadas tendo como referência a proposta educativa e os princípios pedagógicos da educação do MST que são: a relação teoria e prática, educação pelo e para o trabalho, auto-organização dos estudantes, gestão democrática, criação de coletivos pedagógicos. Esses princípios balizaram a escola a se organizar com tempos e espaços educativos, espaços de auto-organização dos estudantes e um vínculo direto com a luta por Reforma Agrária (MST, 2005).

No âmbito do ensino, o MST/PR se referenciou até 2011/12, nos temas geradores. De acordo com Freire (2005), o trabalho com o tema gerador deve levar a uma forma crítica de pensar o mundo. Os temas geradores se constituem como elos, que articulados vão promovendo o estudo da realidade local sem deixar de lado a realidade regional, nacional e internacional.

A pretensão da Escola Itinerante com a organização curricular por temas geradores, era o estudo em conexão com a vida, na busca de compreender as contradições, os problemas da realidade e sua transformação, realizando a práxis (ação-reflexão-ação) e, desde a concretude da vida realizar o estudo, situando geográfica, política, social e culturalmente o estudante. Todo esse processo, como afirma Freire (2005), é de leitura e releitura do mundo, das palavras, do pensamento, das ações, das escolhas, das opressões, as quais passam a ser escritas, lidas e debatidas, como forma de construção da consciência coletiva de libertação.

Porém, as Escolas Itinerantes encontraram limites no trabalho com o tema gerador, de acordo com Mariano (2011, p. 54): 


\section{Revista \\ Debates Insubmissos}

A forma que as Escolas Itinerantes têm trabalhado o tema gerador, ora tem teorizado os problemas da realidade, não conseguindo retomá-los nas situações de ensino, o que os distancia da vida; ora tem favorecido uma postura espontânea no que se refere aos conhecimentos que devem ser ensinados nos programas de ensino, sendo priorizado somente os conhecimentos que os temas exigem abordar, deixando de fora alguns saberes que são importantes para a formação do sujeito.

No ano de 2009, no processo de registros e reflexões de experiências das Escolas Itinerantes, compondo a coleção de cadernos das Escolas Itinerantes, que envolveu representantes do MST, de Universidades e do Setor de Educação do Paraná, identificou-se a seguinte problemática: nas Escolas Itinerantes nas modalidades da Educação Infantil e anos iniciais do Ensino Fundamental se evidenciava avanços da proposta, como: a autoorganização dos estudantes, o ensino por temas geradores, ensino em conexão com a vida, conteúdos contextualizados, a identidade de luta e pertencimento de classe pelos estudantes e professores. Porém, nos Anos Finais do Ensino Fundamental e Ensino Médio já não se evidenciava o mesmo; ao contrário, o que se percebia era um ensino igual à escola padrão da rede de ensino, com aulas descontextualizadas, estanques nos horários da escola, com estudantes desmotivados, sem pertença de classe ou grupo. Também se percebia uma relativização no ensino dos conteúdos universais das ciências, filosofia e arte.

No ano de 2009, no processo de registros e reflexões de experiências das Escolas Itinerantes, compondo a coleção de cadernos das Escolas Itinerantes, que envolveu representantes do MST, de Universidades e do Setor de Educação do Paraná, identificou-se a seguinte problemática: nas Escolas Itinerantes nas modalidades da Educação Infantil e anos iniciais do Ensino Fundamental se evidenciava avanços da proposta, como: a autoorganização dos estudantes, o ensino por temas geradores, ensino em conexão com a vida, conteúdos contextualizados, a identidade de luta e pertencimento de classe pelos estudantes e professores. Porém, nos Anos Finais do Ensino Fundamental e Ensino Médio já não se evidenciava o mesmo; ao contrário, o que se percebia era um ensino igual à escola padrão da rede de ensino, com aulas descontextualizadas, estanques nos horários da escola, com estudantes desmotivados, sem pertença de classe ou grupo. Também se percebia uma relativização no ensino dos conteúdos universais das ciências, filosofia e arte. 
A partir dessas preocupações, o Setor de Educação do MST decidiu aprofundar estudos da proposta da Escola Comuna (PISTRAK, 2009), contando com aporte teórico do Prof. Dr. Luiz Carlos de Freitas (UNICAMP). A pesquisadora Marlene Sapelli (SAPELLI, 2013, p. 147), ao registrar esse processo de construção da proposta pedagógica do experimento dos complexos de Estudos afirma que:

Em 2010 (maio e outubro) e 2011 (junho, agosto, outubro e novembro) houve seis encontros para a construção da Proposta dos Complexos de Estudo (o último só da coordenação). A assessoria principal foi dada por Luiz Carlos de Freitas (UNICAMP) e Roseli Salete Caldart (ITERRA/MST).

Esse processo de construção da proposta pedagógica dos complexos de Estudos tomou por base a proposta pedagógica das escolas do MST e seu projeto educativo, como também buscou se apropriar da proposta da Escola Comuna da União Soviética, tomando por base os avanços e principalmente seus limites. Conforme descreve Sapelli (2013, p. 147):

\begin{abstract}
Muitos momentos desses encontros foram de estudo com Freitas para que o grupo compreendesse a proposta dos complexos. Logo no início dos trabalhos, Freitas indicou que a experimentação com os Complexos de Estudo não representava a transposição da experiência russa, mas que ela seria ponto de partida e também que não havia incompatibilidade entre a proposta dos Complexos e dos Ciclos de Formação Humana. Também definiu três níveis para a elaboração da proposta: do sistema (define o currículo e as ligações gerais com a vida e a abordagem metodológica geral), do coletivo escolar (que lidera a adequação das decisões tomadas ao nível do sistema ao entorno da escola, concreta) e de preparação do magistério (que precisa conhecer todo o sistema de produção dos complexos para poder aplicá-lo).
\end{abstract}

Nesse processo de construção da proposta curricular, o MST não abandonou os temas geradores e nem a Pedagogia do Movimento (CALDART, 2004), mas buscou a superação dos limites avaliados, incorporando aquilo que havia acumulado e que considerou como base para a continuidade do processo de construção da proposta pedagógica. Conforme constata Sapelli (2013, p.140), foi a partir desses entendimentos, reconhecendo a contribuição de Paulo Freire para construir o caminho e a identidade pedagógica, é que o Movimento continua a caminhar, buscando na proposta soviética do início do século XX, elementos que desenvolvam outras dimensões da formação humana e que recoloque entre elas a dimensão da apropriação do conhecimento produzido social e historicamente. 
Ao final de 2012, o Setor de Educação do MST com aporte de uma equipe de intelectuais colaboradores, de educadores das Escolas Itinerantes e de representantes do Setor Estadual de Educação do MST, concluiu a elaboração da proposta pedagógica do experimento dos Complexos de Estudo, sistematizada num documento chamado Plano de Estudos (FREITAS, CALDART, SAPELLI, 2013).

\section{A MATRIZ DO TRABALHO E OS FUNDAMENTOS TEÓRICO- METODOLÓGICOS DA PROPOSTA CURRICULAR}

Nesse caminho, para fazer uma escola comprometida com um projeto de classe, as Escolas Itinerantes buscaram aprender com outras experiências da classe trabalhadora, se referenciando na Escola do Trabalho experimentada na União Soviética entre os anos de 1918 a 1930. A principal categoria aprofundada na proposta pedagógica do MST foi o trabalho socialmente necessário, que é categoria imprescindível para compreensão do homem e da sociedade. Para Freitas (2009, p. 34):

O trabalho socialmente útil é, exatamente, o elo perdido da escola capitalista. O trabalho socialmente útil é a conexão entre a tão propalada teoria e prática. É pelo trabalho, em sentido amplo, que esta relação se materializa. Daí a máxima: não basta compreender o mundo, é preciso transformá-lo. A escola é um instrumento de luta no sentido de que permite compreender melhor o mundo (domínio da ciência e da técnica) com a finalidade de transformá-lo, segundo os interesses e anseios da classe trabalhadora (do campo e da cidade), pelo trabalho.

Tomar o trabalho como categoria central possibilita explicitar as contradições da sociedade, uma tarefa que a escola liberal burguesa não pode fazer, pois assumiria uma postura contrária à sua natureza - produção da submissão. O trabalho, na atual forma de escola, é referenciado de forma unilateral, desvinculado da totalidade social, das contradições e do desenvolvimento histórico da sociedade de classes. De acordo com Freitas (2009), o trabalho é tomado idealmente como base para a formação de trabalhadores para o mercado de trabalho capitalista, com a alienação, subserviência e resignação a ele necessárias.

O conceito de atualidade desenvolvido por Shulgin, permite compreender como o trabalho deve adentrar na escola. Segundo Shulgin apud Freitas (2009, p. 33) 


\section{noviste \\ Debates Insubmissos}

O trabalho vai se constituindo como fundamento da vida, nas suas várias manifestações, inclusive na fábrica que para ele concentra, naquele momento histórico, a atualidade e é o "nervo da vida mundial", sempre em movimento, sempre em processo. Aqui se colocam as questões da politecnia. "A fábrica é o melhor lugar para se familiarizar com os ideais proletários. A fábrica mais facilmente liga-se com o trabalho mundial. Assim, se junta na unidade de nossas exigências fundamentais. Daí a necessidade de forjá-las a partir dos objetivos da educação".

Pistrak (2009) demonstra igual preocupação com o trabalho, na perspectiva de conectá-lo com os conhecimentos, entendendo que a busca de compreensão da realidade exige um conhecimento vivo e interdisciplinar.

$\mathrm{Na}$ escola capitalista, o conhecimento é um produto que se vende e troca; é um fim em si mesmo, por isso se encontra artificializado, fracionado, apartado da vida. Na Escola do Trabalho o ensino e a educação visam a "transformação dos conhecimentos em concepções ativas", isto é, voltam-se para a realidade no sentido de compreendê-la de forma crítica e superadora. De forma que o estudante deve sempre compreender a si mesmo situado socialmente e consciente de suas possibilidades e da direção de suas ações. Esta posição da escola de Pistrak não o levou jamais a relativizar a importância do acesso ao conhecimento e especificamente à ciência. Ao contrário, os desafios colocados para edificação da sociedade socialista, nas condições mais adversas, exigiam o domínio dos métodos científicos (PISTRAK, 2009).

A este respeito são pertinentes as considerações de Shulgin apud Pistrak (2009):

Nós não precisamos de selvagens civilizados, executores obedientes, escravos e, portanto, eles devem conhecer a atualidade, poder lutar, poder construir; eis porque nós não precisamos de muralhas monásticas, não do isolamento das crianças da vida, não raptá-las, não da história antediluviana, não da técnica e ciência antiquadas, não de professores antiquados, afastados da atualidade. Não, nós precisamos da escola cada vez mais integralmente, de cima para baixo, impregnada pela atualidade; nós precisamos de professores que compreendam a atualidade, que tomem parte de sua construção, nós precisamos da criança viva. Como atingir isso? É pouco conhecer os ideais da classe trabalhadora, é pouco querer construir. É preciso viver os ideais da classe trabalhadora, é preciso poder lutar por eles, é preciso poder construir.

A escola do trabalho tem na auto-organização dos estudantes um elemento essencial. Esta formulação encontra sua inspiração na construção do socialismo russo, que, na época de Pistrak, encontrava-se nas mãos das massas trabalhadoras. A questão que se colocava para Pistrak era como a escola poderia formar seus jovens estudantes para que fossem os 


\section{novistet

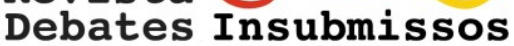

construtores do amanhã? Pistrak estava convencido que as crianças e jovens deveriam experimentar na própria escola formas de organização e participação que desenvolvessem a capacidade de coordenar e ser coordenado (ou comandar e ser comandado), de crítica e autocrítica, de iniciativa, de inserção na organização coletiva.

A criança e, sobretudo, o adolescente não se preparam apenas para viver, mas já vivem uma verdadeira vida. A auto-organização deve ser para eles um trabalho sério, compreendendo obrigações e sérias responsabilidades. Se quisermos que as crianças conservem interesse pela escola, considerando-a como seu centro vital, como sua organização, é preciso nunca perder de vista que as crianças não se preparam para se tornar membros da sociedade, mas já o são, tendo seus problemas, seus interesses, objetivos, ideais, já estando ligadas à vida dos adultos e do conjunto da sociedade (PISTRAK, 2000, p .42-43).

A escola experimentada na URSS fundamentou-se em Marx (1987) e buscava formar para a democracia, participação, organização, crítica e autonomia, o que os estudantes exercitavam em seu interior. A proposta da Escola Comuna conectou a escola no processo da revolução da União Soviética e guiou a escola para a centralidade dos objetivos formativos da classe trabalhadora, como explicita Shulgin apud Pistrak (2009, p. 30):

Formar os lutadores pelos ideais da classe trabalhadora, construtores da sociedade comunista - tais são os objetivos da escola. Mas o que isso significa? Que exigências obrigatórias decorrem disso? Para atingir estes objetivos é necessário, claro, conhecer os ideais da classe trabalhadora, é preciso saber trabalhar coletivamente, viver coletivamente, construir coletivamente, é preciso saber lutar pelos ideais da classe trabalhadora, lutar tenazmente, sem trégua; é preciso saber organizar a luta, organizar a vida coletiva, e para isso é preciso aprender, não de imediato, mas desde a mais tenra idade o caminho do trabalho independente, a construção do coletivo independente, pelo caminho do desenvolvimento de hábitos e habilidades de organização. Nisto constitui o fundamento da tarefa da autogestão.

As categorias centrais presentes na obra organizada por Pistrak (2000) portanto são trabalho, atualidade e auto-organização. O trabalho socialmente útil é a conexão entre a teoria e a prática, numa escola que, diferente do "escolanovismo", não imita a vida, mas conecta-se com ela. A escola é vista como um prolongamento do meio e não uma preparação para ele. Funde-se ao meio, à vida e ao mundo do trabalho com toda sua complexidade e com todas as suas contradições.

Sobre a matriz do trabalho, é importante considerar ainda, nessa análise a necessidade de superação do caráter de alienação do trabalho. De acordo com Manacorda (2007) considerando a dimensão sócio-histórica do trabalho e da educação, é necessário compreendê- 
los no contexto do capitalismo. Neste modo de produção, é necessário observarmos a natureza contraditória do trabalho. O trabalho no capitalismo, separado do seu sujeito e transformado em substância da relação valor de troca, portanto, produtor de mais-valia está subordinado ao capital, gera alienação, a qual afeta o próprio gênero humano. Com base na crítica à divisão do trabalho, que influencia as mentes e os corpos dos trabalhadores, Marx (1987) propõe a união entre a escola e o trabalho, tendo como ponto de partida o concreto real, esse intento, que o ensino por complexos busca realizar.

\section{A PROPOSTA CURRICULAR DOS COMPLEXOS DE ESTUDOS NAS ESCOLAS DO MST}

Com esses fundamentos se engendrou a Proposta Curricular em Complexos de Estudo das Escolas Itinerantes do MST/PR, que tem como objetivo, de acordo com FREITAS, CALDART, SAPELLI (2013, p. 11):

[...] desenvolver e formar seres humanos que sejam capazes e queiram assumir-se como lutadores, continuando as lutas sociais de que são herdeiros, e construtores de novas relações sociais, a começar pelos acampamentos e assentamentos onde vivem e que são desafiados a tornar espaços de vida humana criadora.

Para isso, se intenciona métodos pedagógicos que busquem o desenvolvimento de uma visão de mundo que atinja estes objetivos; educando as crianças e jovens para serem ativos, com iniciativa, multilateralmente desenvolvidos, com apropriação de conhecimentos científicos relevantes, capazes de ligar teoria e prática, que aprendam habilidades técnicas, hábitos sociais e valores de convivência e trabalho coletivo.

Apresenta como premissa outra forma escolar, que descentre o ensino da sala de aula, conectando os conteúdos com a vida, para isso aponta a excursão pedagógica e a identificação das fontes educativas. Como síntese, o complexo é a unidade de diversas categorias pedagógicas evocadas, conforme ilustra a figura que segue: 
Figura - 01 Apresentação Complexos de Estudo

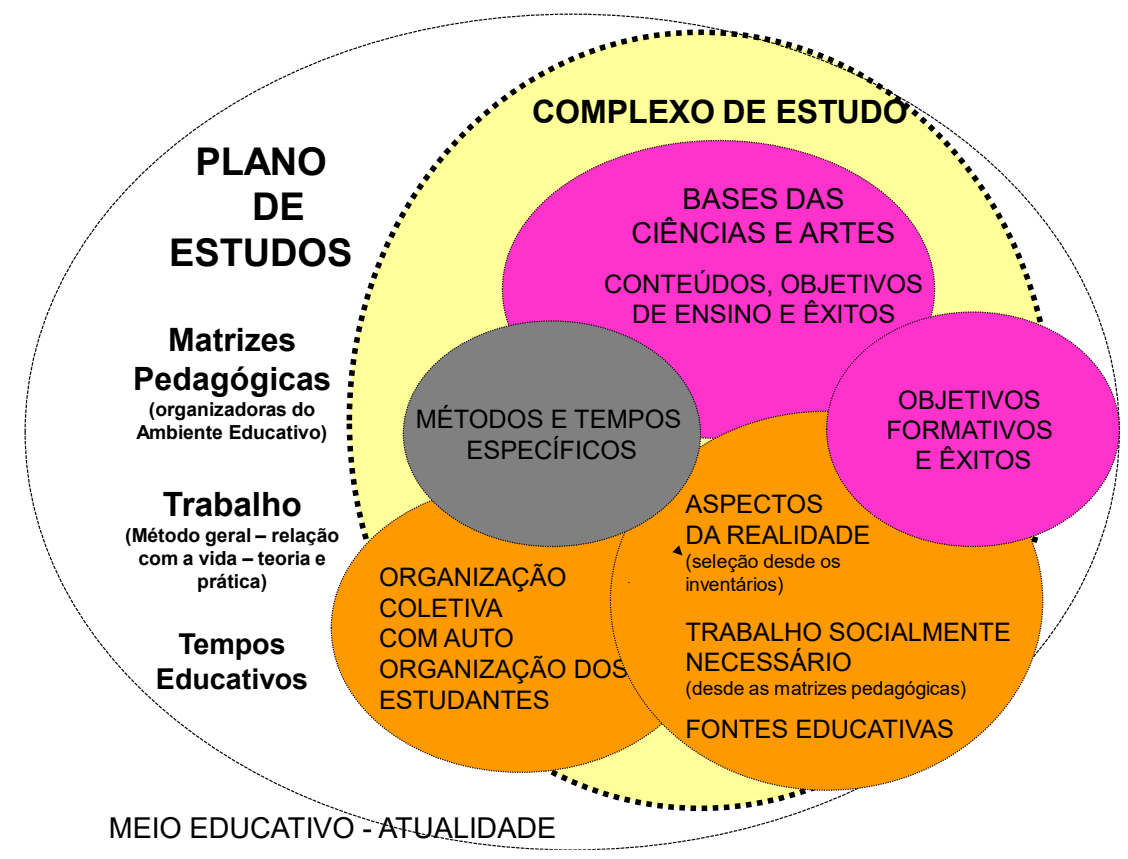

Fonte: FREITAS, L.C; CALDART, R.S; SAPELLI, 2013.

Na formulação da proposta o termo Complexos de Estudo (FREITAS, CALDART, SAPELLI, 2013), se caracteriza por três aspectos: primeiro, a representação de uma "complexidade" que envolve um conjunto de conhecimentos, que deve ser desvelado pelos estudantes com ajuda dos professores, utilizando e se apropriando de conceitos, categorias das várias ciências e artes que são objetos de ensino de um determinado ano escolar.

Segundo, o complexo tem uma prática social real embutida em sua definição, ou seja, deve conter o trabalho socialmente necessário, possibilita o ensino dos conteúdos na vida, na concretude em torno da escola e também articula com o elemento da auto-organização dos estudantes e terceiro, é o palco de uma exercitação teórico-prática que exige do estudante as bases conceituais para seu entendimento, permite criar situações para exercitação prática destas bases plenas de significação e desafios e ao mesmo tempo possibilita que estes conceitos sejam construídos na interface da contribuição das várias disciplinas responsáveis pela condução do complexo. Ele é mais que um tema ou eixo e não se resume à idealização de 
uma prática que apenas anuncia a aplicabilidade longínqua de uma aprendizagem (FREITAS, CALDART, SAPELLI, 2013). E ainda:

O complexo é uma unidade curricular do plano de estudos, multifacetada, que eleva a compreensão do estudante a partir de sua exercitação em uma porção da realidade plena de significações para ele. Por isso, o complexo é indicado a partir de uma pesquisa anteriormente feita na própria realidade das escolas itinerantes. É uma exercitação teórico-prática que acontece na realidade existente no mundo do estudante, vivenciada regularmente por ele em sua materialidade cotidiana e que agora precisa ter sua compreensão teórica elevada. (FREITAS, CALDART, SAPELLI, 2013, p. 31).

Em síntese, pode se afirmar que cada Complexo de Estudo é uma unidade curricular do plano de estudos, que articula trabalho, auto-organização, matrizes formativas, bases das ciências, ou seja, tem uma composição multifacetada, e a escola deve colocar todas em movimento, desde o plano de ensino, a gestão participativa, o trabalho, entre outros, os educandos(as) aprendem e se desenvolvem, eleva o conhecimento a partir de sua exercitação teórico-prática que acontece na realidade existente na vida do estudante, em sua materialidade cotidiana e que passa a ter sua compreensão teórica elevada. Por isso, o complexo demanda anteriormente a pesquisa feita na própria realidade das Escolas Itinerantes, para poder ancorar os conteúdos na materialidade em torno da escola.

\section{AUTO-ORGANIZAÇÃO DOS ESTUDANTES E UMA NOVA FORMA ESCOLAR}

$\mathrm{Na}$ busca de uma nova forma escolar, condizente com os objetivos formativos da proposta pedagógica dos Complexos de Estudos, sistematizada no Plano de Estudos (2013), percebeu-se a necessidade da subversão da forma escolar clássica, na qual a sala de aula é espaço central de referência para a organização dos agrupamentos de estudantes, centrada numa estrutura de poder em que o professor é autoridade máxima em relação aos estudantes, com um conjunto de papéis já determinado.

Todavia, diante dos limites enfrentados para mudar a relação na sala de aula, na qual a aprendizagem está limitada à transmissão do trabalho humano sem nexos com a atualidade, em um modelo de escola em que professor e aluno ficam submissos a regras de dominação legal, é preciso a criação de espaços em que os estudantes possam exercitar mais autonomia 


\section{Revista (O) \\ Debates Insubmissos}

para coordenar, propor soluções, se auto-organizarem e implementar as decisões. É preciso ainda, aprender a decidir e gestar processos coletivos, além de exercitar o trabalho associado e cooperado.

Na experiência da Escola Comuna da URSS, no período pós-revolução (1917-1924), buscou-se colocar a escola nas mãos dos estudantes, organizando a escola do trabalho, com comissões e assembleias. Conforme registra Pistrak (2009), a vida da comuna, portanto, está nas mãos dos estudantes. As tarefas são concretas e inadiáveis. O trabalho é real e não de "brincadeira". As consequências do trabalho e do não trabalho são igualmente concretas e afetam o dia a dia de todos. As comissões, a assembleia, enfim, os órgãos coletivos são palco de vivências e grandes mediadores. A Escola inteira ensina (PISTRAK, 2009, p.31). Na Pedagogia do Movimento Sem Terra (CALDART, 2004), se exercita a autogestão, espaço em que as famílias Sem Terra são envolvidas em sua estrutura organizativa horizontalizada; organizadas em instâncias de participação, em acampamentos ou assentamentos.

Exercita-se a construção de espaços coletivos, com objetivo de garantir a participação de todos(as) Sem Terra nos processos de decisão e ação, por meio de princípios organizativos como direção coletiva, estudo, disciplina e planejamento, desde os núcleos de base até a direção nacional do MST. Conforme o Caderno de Educação no 9 do MST (1999), a proposta de educação do Movimento inova em formas e espaços de organização para estudantes, professores e comunidade, devendo funcionar de forma planejada, coletiva e solidária. Propõe, efetivamente, uma nova forma escolar, composta de quatro aspectos.

O primeiro aspecto é a estrutura orgânica da escola: embasada na forma de organização dos acampamentos, com princípios de gestão democrática, auto-organização dos estudantes, coletivos pedagógicos, direção coletiva e divisão de tarefas. O segundo é o ambiente educativo, que assinala a importância de organização dos espaços e relações na escola, a fim de educar o ser humano integralmente e em sintonia com o projeto do MST, por isso propõe tempos educativos como aula, trabalho, oficina, esporte/lazer, estudo, mutirão, coletivo pedagógico; e relações pautadas pela luta, mística, ecologia, entre outros valores. 
O terceiro aspecto se refere à matriz formativa do trabalho e discorre sobre a importância de espaços distintos de trabalho para os estudantes na escola e a relação desta com o trabalho realizado na família e com outras formas de trabalho. Objetiva-se desenvolver, dentre as várias possibilidades emanadas dessa dimensão, especialmente a cooperação, a agroecologia e a experiência da produção material da vida. No quarto e último aspecto apresenta-se formas de estudos para além das aulas, propondo, inclusive, uma dinâmica distinta de organização desta, tendo como objetivo o máximo envolvimento dos educandos(as) na produção do conhecimento. Estes aspectos do projeto de educação do MST e da experiência da escola Comuna foram ponto de partida para proposição de uma forma escolar objetivando a formação de lutadores e construtores, visando acompanhar a atualidade da luta do MST, que no seu último congresso, em fevereiro de 2014, lançou o lema "Lutar, construir, reforma Agrária Popular”!

Nesta experiência em construção a autogestão pretende o fortalecimento de uma coletividade que se autogoverna, que cria espaços para propor e decidir sobre a dinâmica do trabalho pedagógico e a administração da escola como um todo. Assim sendo, a forma escolar pretende uma educação não autoritária que iniba mecanismos de submissão e conformidade. Construiu-se, assim, a forma escolar da proposta pedagógica dos complexos de estudos que tem como princípio a autogestão, ou seja, participação de todos(as) no processo de decisão do processo educativo escolar e comunitário, mas também de implementação do que foi decidido, e para isso é necessária uma estrutura organizativa que proporciona relações sociais igualitárias entre os diferentes sujeitos que formam o coletivo escolar e as instâncias do acampamento/assentamento. Na proposta curricular dos complexos de estudos a autoorganização constitui por três aspectos centrais: autogestão, estrutura organizativa da escola e núcleos setoriais. (MARIANO, 2016)

\subsection{Autogestão}

O mecanismo de subversão da forma escolar clássica que foi adotada é a constituição de formas de organização coletiva que alterem a lógica de poder, horizontalizando as relações entre educandos(as) e educadores(as) para que dividam tarefas no cotidiano escolar e também na vida comunitária, compreendendo cientificamente os fenômenos da realidade desde as 


\section{Revista $\bigcirc$ \\ Debates Insubmissos}

bases das ciências nas disciplinas, mas também fazendo intervenções na vida da comunidade com trabalho socialmente necessário, com proposições nas instâncias da comunidade e participação nas ações de luta como classe trabalhadora.

Para a pedagogia socialista, desde a contribuição de Pistrak (2000) ao conectar a escola no processo de luta da classe trabalhadora por transformações sociais e estruturais na sociedade, há outras exigências formativas a cumprir.

É preciso que a nova geração compreenda, em primeiro lugar, qual é a natureza da luta travada atualmente pela humanidade; em segundo lugar, qual o espaço ocupado pela classe explorada nesta luta; em terceiro lugar, qual o espaço que deve ser ocupado por cada adolescente; e, finalmente, que cada um saiba, em seus respectivos espaços, travar a luta pela destruição das formas inúteis, substituindo-as por um novo edifício (PISTRAK, 2000, p. 31).

O processo de autogestão toma como base os desafios de funcionamento e gestão do cotidiano escolar, relacionando-os aos desafios da comunidade. Se cair uma ponte que dá acesso ao assentamento/acampamento, por exemplo, os estudantes do ensino médio podem se juntar aos adultos da comunidade e reconstruir a ponte; se a comunidade se deparar com uma epidemia, os estudantes podem contribuir com informações ou auxiliar para acabar com foco da doença, etc.

Outro desafio ao qual a autogestão se conecta é a luta pela Reforma Agrária, pois, além de estudar sobre, participam da sua construção. Organizam-se desde os coletivos estudantis para participar das jornadas de luta, mobilizações, ocupações de pedágios, etc. Assim, o ensino e a auto-organização perpassam o cotidiano da escola, atrelados à intencionalidade formativa para a construção de lutadores e construtores de uma sociedade mais justa.

Segundo Pistrak (2000), os fundamentos da autogestão são necessários para constituir hábitos de saber trabalhar, viver e construir coletivamente. É preciso saber lutar pelos ideais da classe trabalhadora, lutar tenazmente, sem trégua; é preciso saber organizar a luta, organizar a vida coletiva e para isso é preciso aprender, desde a mais tenra idade, o caminho do trabalho independente, de coletivos independentes, por meio do desenvolvimento de 


\section{Revista \\ Debates Insubmissos}

hábitos e habilidades de organização coletiva. Conforme Pistrak (2009, p. 247), o valor pedagógico da auto-organização é “determinado como método de trabalho formativo/educativo da criança e do adolescente consigo mesmo e com o meio social, com a ajuda do adulto".

Deste modo, o papel dos educadores é imprescindível, pois a horizontalização das relações não significa a transferência da função do ensino e de intencionalidades formativas que devem ser assegurados pelos educadores, tampouco significa ignorar a institucionalidade vigente, suas leis e dispositivos. Trata-se de criar mecanismos participativos que exercitem a capacidade de organização e de decisão dos estudantes para que aprendam a coordenar e serem coordenados, e principalmente, que desenvolvam posturas de sujeitos construtores de relações sociais que questionem a lógica da propriedade privada.

Estes espaços de organização política são vistos como possibilidades formativas dos estudantes, porque desenvolvem habilidades para se auto-organizarem, exercitando a dimensão do trabalho coletivo, ensino e gestão da escola. Para que esta forma de organização seja possível a escola precisa redimensionar o seu tempo. Deste modo, os tempos e espaços previstos visam articular estas dimensões na formação dos estudantes, que permitem a sua autonomia.

A Escola Itinerante, como vimos anteriormente, assume o trabalho como categoria central de sua proposta pedagógica e deste modo a forma escolar buscou fazer articulação entre o trabalho, auto-organização e ensino. Assim foi construída a estrutura organizativa composta por espaços de participação coletiva, sendo eles: núcleos setoriais, coordenação executiva, assembleia e os demais espaços educativos que proporcionam alcançar as intencionalidades educativas da proposta.

\subsection{Estrutura organizativa da escola}

A estrutura organizativa é o jeito de organizar a gestão da Escola, engloba a organização e as relações entre as instâncias que devem ser planejadas e acompanhadas como parte do processo pedagógico, condizente com as várias dimensões de nossa matriz formativa postas em marcha e se desenvolvem em consonância com o desenvolvimento cognitivo do 


\section{Revista

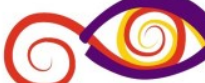 \\ Debates Insubmissos}

estudante. Não bastam, aqui, mecanismos de cunho representativo, nos quais os educandos são sempre representados de forma minoritária; como os conselhos escolares, por exemplo. Trata-se de permitir a condução de processos escolares com apoio e orientação dos educadores. Processos esses que implicam responsabilização real pelo cumprimento de objetivos que afetam a vida de todos.

Vejamos o desenho da estrutura organizativa que é usada nas Escolas Itinerantes, a qual busca responder aos princípios da coletividade e auto-organização:

Figura - 02 Estrutura organizativa da Escola Itinerante

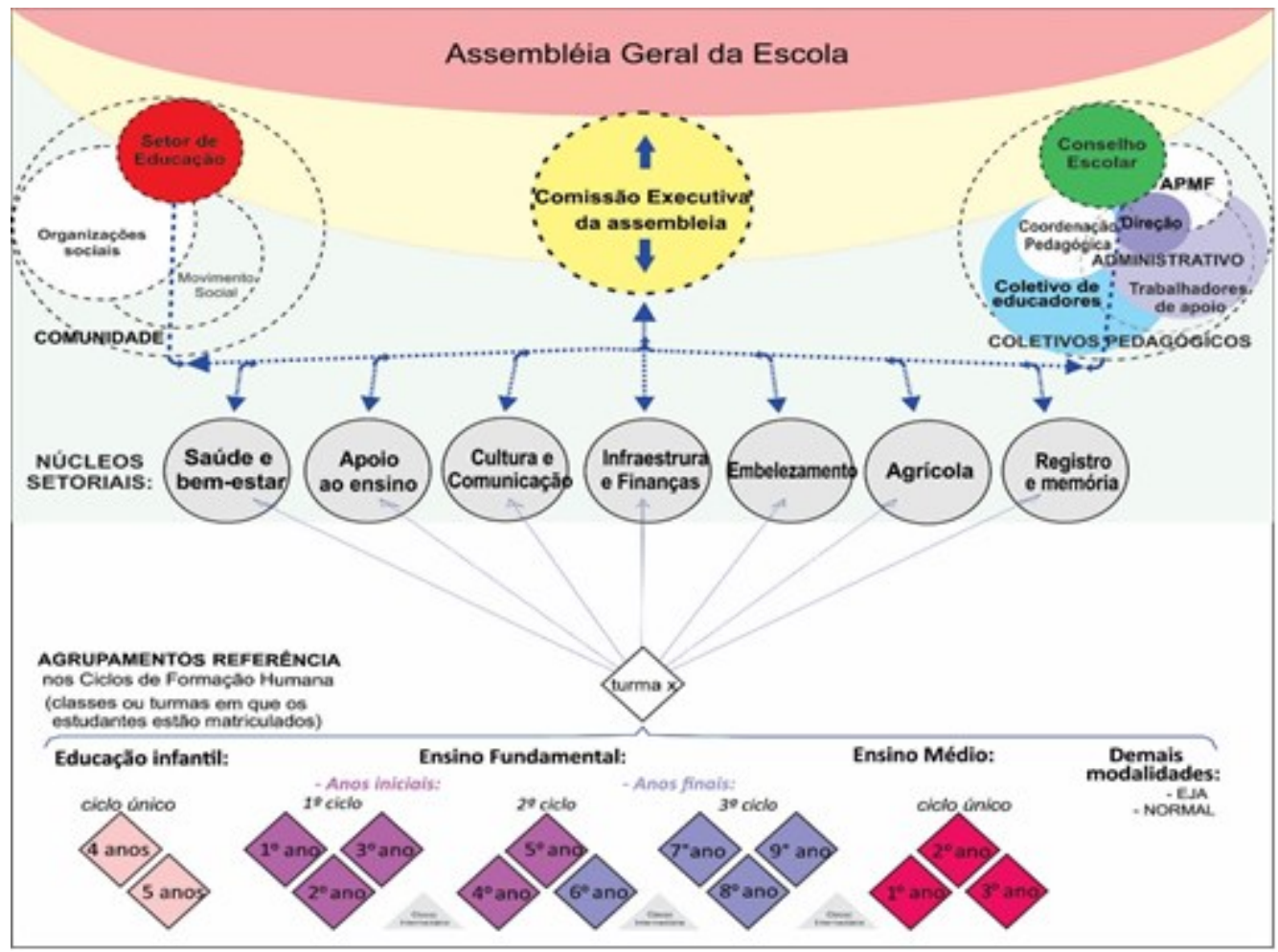

Fonte: FREITAS, L.C; CALDART, R.S; SAPELLI, 2013.

De forma ascendente, veremos primeiramente as turmas (os agrupamentos de referência por ano, condicionado ao planejamento de ensino docente). Logo depois, os Núcleos Setoriais agrupam estudantes das diferentes turmas e neste espaço/tempo articulam ações práticas específicas da função de cada núcleo e possíveis trabalhos demandados pela 


\section{Revista $(0)$ \\ Debates Insubmissos}

articulação de determinada porção da realidade em execução. A organização destes núcleos acontece mediante as demandas reais de cada escola.

A Coordenação da escola é composta pelos estudantes responsáveis (coordenadores dos Núcleos Setoriais). É neste espaço que se unificam as diferentes ações que movimentam a escola em cada período letivo. Os coordenadores dos Núcleos devem ser trocados de tempos em tempos, para que todos aprendam a coordenar e serem coordenados, garantindo assim a participação efetiva de todos em processos coletivos e complexos na escola. Se olharmos de forma descendente temos no topo, a assembleia, ela é a instância máxima da escola e pode acontecer no início e no final de cada semestre, com participação dos educandos, educadores e funcionários. $\mathrm{Na}$ assembleia são socializados encaminhamentos que movimentam a escola, articulando o trabalho específico dos núcleos setoriais, o ensino e a gestão da escola com ações que envolvem a comunidade. A coordenação executiva da escola, composta pelos coordenadores dos núcleos setoriais, é responsável por zelar e executar o cumprimento das decisões coletivas tomadas em assembleia. Deste modo, os núcleos setoriais tornam-se espaço de execução do trabalho, mas também de estudo e gestão da escola.

\subsection{Núcleos Setoriais}

Os núcleos setoriais são células organizativas da Escola Itinerante, constituem-se em espaços para os educandos exercitarem a auto-organização e o trabalho real. Essas duas terminologias "núcleo" e "setorial" têm origem na estrutura organizativa do MST, que concebe o "núcleo de base" como uma célula organizativa do movimento em cada assentamento/acampamento. Os núcleos de base são geralmente formados por 7 a 10 famílias, representadas por um coordenador e uma coordenadora, podemos também chamá-los de espaços de decisões da organização local. A terminologia "setorial" referencia-se nos setores do movimento, que assumem um conjunto de tarefas da organização, sendo eles: produção, saúde e gênero, comunicação e cultura, finança, formação, frente de massa e educação.

Os Núcleos Setoriais são organizados com reagrupamento horizontal de várias idades e anos, durante o turno ou contra turno escolar. A quantidade de núcleos setoriais é determinada pelos principais aspectos da vida, que a escola identifica que necessitam da 


\section{Revista
Debates Insubmissos}

intervenção real dos estudantes, por isso é preciso organizar um certo número de núcleos encarregados destes aspectos. Alguns exemplos de núcleos setoriais são: memória, comunicação, apoio ao ensino, embelezamento, agrícola, saúde e bem-estar, finança e infraestrutura.

Conforme afirmamos anteriormente, o núcleo setorial é uma célula organizativa da escola em que todos os educandos fazem parte, se constituindo em um espaço de autoorganização em torno de tarefas, trabalho de autosserviço na escola e pode, mediante o planejamento coletivo dos educadores ou mesmo da especificidade de cada núcleo, movimentar o trabalho socialmente necessário, articulando as bases da ciência e da arte à vida. Assumem duas funções específicas, uma delas voltada à especificidade do trabalho que desenvolvem; a outra voltada às dimensões do todo da escola, que perpassa pela dimensão da gestão desta forma escolar, movimentada pela metodologia de trabalho dos Complexos de Estudo. Os líderes dos núcleos setoriais não são permanentes, a alternância na coordenação é praticada semestralmente para que vários estudantes tenham a experiência de liderar.

A escolha das lideranças é realizada por eleição nos núcleos de base e podem se candidatar aqueles que têm referência de participação, disciplina no estudo e no trabalho, respeito às decisões da coletividade e capacidade de liderança. Outro aspecto é a relação dos núcleos setoriais aliados ao ensino (conteúdos das disciplinas), que em certos momentos podem ser demandadas especificamente pelas tarefas assumidas pelos estudantes. Abaixo segue um quadro com os principais núcleos setoriais e a relação com o conhecimento: 


\section{Revista \\ Debates Insubmissos}

Quadro 2 - Descrição dos núcleos setoriais

\begin{tabular}{|c|c|c|}
\hline $\begin{array}{l}\text { Núcleo } \\
\text { Setorial }\end{array}$ & Funções que estudantes exercem & Conhecimentos relacionados \\
\hline Memória & $\begin{array}{l}\text { São responsáveis em guardar a memória da escola, } \\
\text { produzem registros escritos da vida coletiva da escola } \\
\text { através de três instrumentos: a) Diário da Escola, b) Pasta } \\
\text { de Acompanhamento das Práticas Pedagógicas dos } \\
\text { Complexos, c) Arquivo Fotográfico e Audiovisual. }\end{array}$ & $\begin{array}{l}\text { Ortografia, redação, tipologias } \\
\text { de textos, organização e } \\
\text { arquivamentos de documentos, } \\
\text { leitura com entonação, etc. }\end{array}$ \\
\hline $\begin{array}{c}\text { Cultura e } \\
\text { Comunicação }\end{array}$ & $\begin{array}{l}\text { Atuam no processo de socialização de informações na } \\
\text { escola e acampamento/assentamento, proporcionando a } \\
\text { todos a conexão com os fatos na escola, na comunidade e } \\
\text { ao em torno. Organizam rádio escolar, jornal e murais. } \\
\text { Realizam leitura do diário no tempo formatura para toda } \\
\text { comunidade escolar. }\end{array}$ & $\begin{array}{l}\text { Diversas linguagens como: } \\
\text { linguagens escritas, faladas e o } \\
\text { domínio das diversas tecnologias } \\
\text { como: rádio, internet, jornal, } \\
\text { mural. }\end{array}$ \\
\hline $\begin{array}{l}\text { Apoio ao } \\
\text { Ensino }\end{array}$ & $\begin{array}{l}\text { Organizam-se em torno da dimensão do ensino na escola e } \\
\text { do acesso ao conhecimento científico, desde o } \\
\text { planejamento de ensino ao cronograma de tempos } \\
\text { educativos; organizam materiais e equipamentos de suporte } \\
\text { ao ensino (televisor, rádio, aparelho de DVD), e os } \\
\text { materiais didáticos, a organização da biblioteca, secretaria } \\
\text { escolar. Recebem visitas na escola e apresentam a proposta } \\
\text { pedagógica e organização no cotidiano escolar. }\end{array}$ & 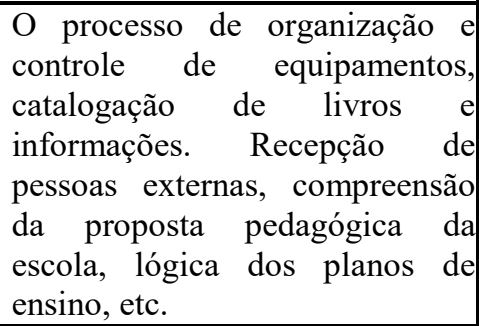 \\
\hline $\begin{array}{c}\text { Finanças e } \\
\text { estrutura }\end{array}$ & $\begin{array}{l}\text { Exercem e acompanham o planejamento financeiro e } \\
\text { administrativo da estrutura da escola. Organizam os } \\
\text { processos de finanças da escola, entradas de recursos, } \\
\text { saídas, planejamento financeiro, prestações de contas. } \\
\text { Fazem controle do patrimônio da escola e da merenda } \\
\text { escolar. }\end{array}$ & $\begin{array}{l}\text { Cálculos, planilha } \\
\text { planejamento eletrônica, } \\
\text { financeira. }\end{array}$ \\
\hline $\begin{array}{l}\text { Embeleza- } \\
\text { mento }\end{array}$ & $\begin{array}{l}\text { Organizam os espaços, possibilitando a primazia do belo na } \\
\text { escola. Proporcionam que os espaços da escola, mesmo } \\
\text { improvisados, sejam acolhedores em harmonia com a } \\
\text { natureza e a produção humana. Auto organizam-se através } \\
\text { de três atividades: plantio de flores, árvores, arbustos, ou } \\
\text { seja, o ajardinamento da escola; a organização estética da } \\
\text { escola: identificação dos espaços, exposição de trabalhos; e } \\
\text { a valorização dos símbolos na escola. }\end{array}$ & 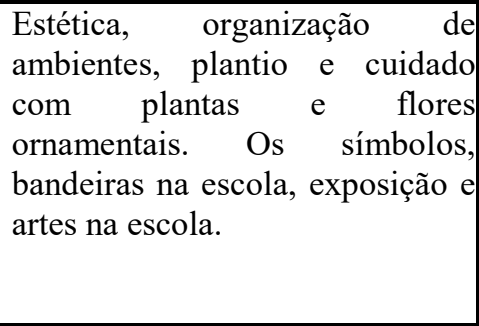 \\
\hline $\begin{array}{c}\text { Saúde e } \\
\text { Bem-Estar }\end{array}$ & $\begin{array}{l}\text { Responsabilizam-se pelo bem-estar da coletividade, que se } \\
\text { preocupa com as diversas questões da vida humana: desde } \\
\text { a alimentação, a limpeza, higiene e saúde. Além de } \\
\text { executarem tarefas práticas de limpeza, fazem orientações } \\
\text { em relação à boa alimentação, cuidado com higiene e } \\
\text { espaços limpos, organizados. }\end{array}$ & $\begin{array}{l}\text { Procedimentos práticos de } \\
\text { limpeza e higiene, bem como a } \\
\text { preparação de } \\
\text { saudáveis. }\end{array}$ \\
\hline Agrícola & $\begin{array}{l}\text { São responsáveis pelas práticas agrícolas na escola e } \\
\text { possibilitam a vivência do cuidado com a terra e com o } \\
\text { meio ambiente. Planejam a produção de alimentos para } \\
\text { consumo na escola e na comunidade através das hortas } \\
\text { agroecológicas, pomar e plantios de outros alimentos, } \\
\text { também a criação de animais. }\end{array}$ & $\begin{array}{l}\text { Práticas da vida no campo, desde } \\
\text { planejar o plantio e a colheita, } \\
\text { com base em conhecimentos } \\
\text { científicos. }\end{array}$ \\
\hline
\end{tabular}

Fonte: Mariano, 2016. 
É a articulação entre trabalho e auto-organização que permite questionar a organização dos tempos e espaços de ensino da escola tradicional. Os pressupostos desta nova forma escolar ensaiam iniciativas importantes na direção de outra forma, que possibilita a formação de lutadores e construtores com capacidade para decidir, organizar, lutar; enfim, construir outras relações sociais para outra forma social. Deste modo, entendemos que os Núcleos Setoriais ensaiam importantes processos organizativos, que influenciam tanto na gestão pedagógica quanto na gestão geral da escola, mediante ações de autogestão, planejadas e executadas pelos educandos na escola. Nestas ações desenvolvem-se outras dimensões importantes para a formação de um ser humano integral, todavia, entendemos que esta forma escolar em construção se realiza mediante os limites da atualidade, pois o desenvolvimento do ser humano omnilateral, conforme destaca Manacorda (2007), somente será possível realizarse de forma plena em outra sociedade, com relações de produção não capitalistas, na qual possam desenvolver as dimensões humanas para além dos limites do trabalho alienado e fragmentado da sociedade capitalista.

\section{CONSIDERAÇÕES FINAIS}

As Escolas Itinerantes do Paraná foram constituídas desde sua origem num processo coletivo, em luta com as famílias Sem Terra, envolvendo todos os educadores(as), comunidade acampada e o Setor de Educação do MST, que pressionam o poder público para seu reconhecimento legal, por isso, sua proposta político-pedagógica se faz em movimento, em avaliação constante, preocupada com a forma e conteúdo escolar. Essas escolas, encontram-se numa realidade de potencialidade, que são os acampamentos, espaço de luta por Reforma Agrária.

Nesse percurso, buscou-se primeiramente uma organização escolar por etapas (20032006), Ciclos de Formação Humana (2007-2011), chegando à formulação da Proposta Curricular dos Ciclos de Formação Humana com Complexos de Estudo (2012), num processo cumulativo de reflexão teórico-prático, aliado aos desafios e perspectiva da luta por transformação social, impulsionado através da luta pela terra e pela organização coletiva dos acampamentos e assentamentos, nos quais estas escolas estão inseridas. 
A Escola Itinerante se vincula à luta e construção da Reforma Agrária Popular e essa é a potencialidade transformadora, isso que impulsiona a construção dessa proposta pedagógica, desde o início as Itinerantes buscaram outra forma de ser e a conexão com a luta dos trabalhadores(as) Sem Terra, que é o cerne, o elemento que impulsiona, que provoca e que conduz a escola a uma prática relacionada com a vida e com a luta da classe trabalhadora, pois essa realidade exige uma escola que ensine além do ler e escrever.

Esse experimento pedagógico, de alguma maneira reconecta-se com esforços dos pedagogos socialistas soviéticos, os quais buscaram construir a Escola do Trabalho, ou seja, uma escola para emancipação dos(as) trabalhadores(as) e nos deixaram um ensinamento, um "segredo" desvelado por eles, que uma das formas de destruir a Escola capitalista é conectando a escola com o trabalho, com a vida e a luta da classe trabalhadora. Buscaram modificar a forma escolar e a do conteúdo de ensino, afirmando que ele deve ser fortemente ligado à construção do socialismo, com as tarefas e os desafios atuais da luta de classes. Mas, no tempo deles, tinham o Estado em suas mãos e colocaram-no a serviço dessa construção e designaram um grupo de trabalhadores(as) da sessão científico-pedagógica da comissão estatal para a elaboração do programa do sistema de complexos.

No caso dessa experiência investigada, aqui no Brasil, em escolas de acampamento do MST, foi a junção de educadores(as) das Escolas Itinerantes em luta que desde a prática pedagógica e acúmulo da pedagogia do MST, da pedagogia do oprimido, do estudos da experiência da Escola Comuna na URSS, formularam uma nova síntese, que foi chamada de Proposta dos Ciclos de Formação Humana com Complexos de Estudo. A intencionalidade formativa se aproxima da mesma dos pedagogos soviéticos, ou seja, proporcionar às crianças, jovens e adultos, a partir da escola, o conhecimento das bases da ciência desde uma visão de mundo socialista, desenvolvendo neles as múltiplas dimensões humanas e junto a isso, a compreensão da vida ao seu redor e as ferramentas para mudá-lo radicalmente, para tal, requer também desenvolver habilidades de trabalhar, organizar-se, estudar, lutar, viver coletivamente.

O experimento curricular nas Escolas Itinerantes do Paraná está em processo. Foi e é feito com muitos limites, mas aponta reflexões importantes acerca da alteração do conteúdo e 
da forma da escola, ao inserir práticas de autogestão, a autodireção e o trabalho, tornando-a viva, inserida na atualidade, com os exercícios de conexão dos conteúdos com a vida, conduzindo os planos de ensino a relacionar o conteúdo escolar (conhecimento vivo) com o trabalho (homem, natureza, sociedade).

As Escolas Itinerantes do Paraná incorporam os elementos dos Complexos de Estudo, que não se opõem aos métodos das disciplinas, mas os relaciona com os fenômenos da realidade, a organização escolar geral. Busca romper com a visão dicotômica entre teoria e prática (o que obtém a partir da centralidade da vida/trabalho no complexo). Dessa forma, não é um método de ensino em si, embora exija métodos, planejamentos, recursos pedagógicos, mas demanda principalmente a concretude da vida, de ensinar trabalhando, lutando e também a relação do todo da escola: base das ciências, auto-organização dos estudantes.

A auto-organização dos estudantes é tomada desde o trabalho e é instrumento de aprendizagem sobre o valor social deste, no sentido do que a comunidade necessita para viver melhor. Esse é um dos avanços até agora da proposta e prática da Escola Itinerante. Desde os núcleos setoriais na Escola Itinerante evidenciam-se os seguintes tipos de trabalho: 1) os trabalhos domésticos, com a intencionalidade dos estudantes aprenderem a realizar tarefas de limpeza, higienização da escola, o preparo de alimentos; 2) o trabalho agrícola, para o exercício de técnicas de produção, práticas de agroecologia desde as hortas escolares, mas também cultivo de pomares de frutas; 3) os trabalhos diversos de registro, que envolve a escrita da memória escolar em texto, fotografia e vídeo, mas também registro e controle do acervo de livros da biblioteca; 4) trabalho desde os instrumentos de comunicação jornal e mural escolar; 5) os trabalhos sociais na comunidade, como conservação de jardins e praças públicas e reflorestamento, que são trabalhos socialmente necessários, porém necessitam de intencionalidade e conexão com os planos de ensino.

Os(as) educadores(as) são desafiados a fazer o ensino a partir de outra matriz e a planejar os conteúdos em conexão com a vida, a pensar o ensino de conteúdos, mas também a formação geral articulada ao que se chama na proposta de objetivos formativos, que tange ao exercício da organização coletiva, o desenvolvimento do trabalho cooperado, a iniciativa para soluções de problemas, pois almeja a formação de estudantes que saibam construir e lutar por 
uma nova sociedade. Os estudantes são desafiados a assumir a condução da escola, desde os núcleos setoriais, o exercício do planejamento e execução do trabalho prático, porém, a maioria restringe-se a práticas de autosserviço, ficando o desafio de avançar no sentido de exercitar o trabalho socialmente necessário.

Percebemos que as práticas de auto-organização, a partir da orientação do plano de estudos, não são totalmente transpostas, como consta no documento, para o cotidiano das escolas por duas razões: pela realidade e condições objetivas das escolas serem distintas e também pela dimensão de planejamento, que cada escola tem autonomia em propor. A unidade está na intencionalidade, que é construir espaços de auto-organização dos estudantes, práticas coletivas de exercitação de novas relações, desde a gestão coletiva, o trabalho não explorado como espaço de produção e reprodução da vida.

As Escolas Itinerantes funcionam em meio à grande precariedade de condições e, mesmo assim, lutam diariamente para a melhoria destas e continuidade do desenvolvimento da proposta. Deste esforço, emergem práticas, ensaiam métodos e formas de fazer formação dos estudantes. As escolas em questão, têm se proposto a fazer novas práticas. Só pelo fato dessas escolas conseguirem refletir sobre o seu fazer pedagógico, construírem outra proposta, exercitarem e experimentarem práticas e métodos, inventar novas formas, mesmo que, com limites, já representam uma positividade, pois essa proposta desafia, envolve, compromete os(as) educadores(as) a serem os sujeitos dela.

Pela dimensão da proposta pedagógica, os(as) educadores(as) têm limites de compreensão da totalidade dela, decorrente do seu processo de formação; da precariedade da infraestrutura; da falta de empenho para aprofundar os estudos; dos problemas internos dos acampamentos e assentamentos; da rotatividade de educadores(as); da falta de materiais de estudo, tanto para os educadores(as) como para os educandos(as); da falta de domínio acerca das propostas e das necessidades de cada disciplina, da dificuldade de realizar planejamento e ações coletivas e tantos outros impostos pela materialidade e condição histórica desse tempo. Mesmo com esses limites, essas escolas representam a possibilidade de exercitar outras práticas educativas e expressam um processo de autogestão da classe trabalhadora que precisa 
ser potencializado, portanto, representam uma alternativa à forma atual da escola, forma essa que busca a formação para o mercado de trabalho, uma formação unilateral.

A alteração da forma escolar não é uma tarefa fácil e os esforços feitos têm demonstrado a rigidez da atual forma da escola, que se expressa na formação dos educadores(as), na forma de organização escolar, no controle do Estado, na matriz cognitiva, dentre outros limites apontados no decorrer desse estudo. Esse experimento curricular é um ensaio da Escola do Trabalho no contexto das lutas do MST, contexto de luta e construção, mesmo que de maneira inicial, em perspectiva, apresenta resultados importantes, principalmente no que se refere à dimensão de projeto educativo de escola, demonstrando a importância das escolas, os(as) seus/suas educadores(as), educandos(as) serem sujeitos da política educacional, e aponta a importância de refletir sobre a intencionalidade educativa da escola, a partir da forma escolar: tempos educativos, a gestão da escola e a auto-organização dos estudantes em relação aos conteúdos e objetivos formativos para a formação e desenvolvimento omnilateral.

\section{REFERÊNCIAS}

CALDART, Roseli Salete. Pedagogia do Movimento Sem Terra.São Paulo: Expressão Popular, 2004.

CAMINI, Isabela. Escola Itinerante: na fronteira de uma nova Escola. São Paulo: Expressão Popular 2009.

FREIRE, Paulo. Pedagogia do Oprimido. 49. Reimp. Rio de Janeiro: Paz e Terra, 2005.

FREITAS, Luiz Carlos. Introdução. In: PISTRAK, M. M. AEscola-Comuna. São Paulo: Expressão. Popular, 2009

FREIITAS, Luiz Carlos; CALDART, Roseli Salete; SAPELLI, Marlene Lucia Siebert.(Orgs). Plano de Estudos da Escola Itinerante, $1^{\circ}$ Ed., Edunioste, Cascavel, 2013.

MANACORDA, Mario Alighiero. Marx e a Pedagogia Moderna. São Paulo, Cortez, 2007.

MARIANO, Alessandro Santos. Escola Itinerante dos Acampamentos do MST no Paraná: limites e possibilidades. UFSC, Florianópolis, 2011. Trabalho de Conclusão de Especialização. 
MARIANO, Alessandro Santos. O experimento curricular dos Complexos de Estudo: práticas de auto-organização dos estudantes e o trabalho socialmente necessário nas Escolas Itinerantes do Paraná. UNIOESTE, Foz do Iguaçu, 2015. Trabalho de Conclusão de Especialização.

MARIANO, Alessandro Santos. Ensaios da Escola do Trabalho no contexto das lutas do MST: a proposta curricular dos ciclos de formação humana com complexos de estudo, nas Escolas Itinerantes no Paraná. Dissertação de mestrado apresentada ao Programa de Pós-Graduação da Universidade Estadual do Centro-Oeste do Paraná - UNICENTRO, 2016.

MARX, Karl. O capital: Crítica da economia política. 11 .ed. São Paulo. DEFEL, 1987. Livro Primeiro volume I.

MARX, Karl; ENGELS, Frederich. O manifesto do partido comunista. Porto Alegre: L\&PM, 2001.

PISTRAK, MoseyMikhaylovich. Fundamentos da escola do trabalho. São Paulo: Expressão Popular, 2000.

PISTRAK, MoseyMikhaylovich. A Escola-Comuna. São Paulo: Expressão Popular, 2009.

SAPELLI, Marlene Lucia Siebert. Escola do Campo - Espaço de disputa e de contradição: análise da Proposta Pedagógica das Escolas Itinerantes do Paraná e do Colégio Imperatriz Dona Leopoldina. Doutorado. Tese apresentada ao Programa de Pós-Graduação da Universidade Federal de Santa Catarina. 2013.

SHULGIN, Victor. Rumo ao politecnismo. São Paulo: Expressão Popular, 2013.

Submetido em: 12/03/2019

Aprovado em: 19/07/2019 